\title{
Coronavirus disease 2019: MRI examination procedures and infection prevention and protection
}

\author{
Xiaoyong Shen ${ }^{1}$, Jinwen Meng ${ }^{2}$, Qidong Wang ${ }^{1}$, Lingmei Ni ${ }^{3}$, Zifeng Zhong ${ }^{3}$, Shaohua $\mathrm{Hu}^{4}$, Feng Chen $^{1}$ \\ ${ }^{1}$ Department of Radiology, ${ }^{2}$ Department of General Surgery, ${ }^{3}$ Department of Infection Control, ${ }^{4}$ Department of Mental Health, the First Affiliated \\ Hospital, School of Medicine, Zhejiang University, Hangzhou, China \\ Contributions: (I) Conception and design: F Chen; (II) Administrative support: F Chen; (III) Provision of study materials or patients: X Shen, Q \\ Wang, S Hu; (IV) Collection and assembly of data: J Meng, X Shen; (V) Data analysis and interpretation: J Meng, Q Wang, S Hu; (VI) Manuscript \\ writing: All authors; (VII) Final approval of manuscript: All authors. \\ Correspondence to: Prof. Feng Chen, MD, PhD. The First Affiliated Hospital, School of Medicine, Zhejiang University, 79 Qing Chun Road, \\ Hangzhou, China. Email: chenfenghz@zju.edu.cn.
}

Background: Though chest computed tomography (CT) and digital radiography (DR) is important in the diagnosis and treatment of COVID-19, for patients with COVID-19 who may need magnetic resonance imaging (MRI) due to other complications, we proposed the MRI procedures for patients and medical staff to reduce the risk of infection between them.

Methods: Combining two cases in our hospital and other literature, a solution about the procedure and necessary preventive and protective measures for MRI examination of COVID-19 patients is proposed for peer reference with the help of experts from our hospital infection-control department. The solution that meets the hospital infection-control regulations covers five aspects including the layout requirements for the MRI room in the radiology department, preparation before admission, preparation of medical staff, preparation of patients, and terminal disinfection after MRI examination. Radiology personnel should strictly abide by the regulations on infection prevention and control. MRI technicians who have been in close contact with COVID-19 patients should receive strict medical observation for two weeks. Each step should be performed carefully to minimize the risk of hospital infection.

Results: A solution that includes five aspects was formulated to prevent the potential contamination during the MRI scan for COVID-19 patients. These five aspects are layout requirements in the MRI room, preparation before admission, preparation of medical staff, preparation of patients, and terminal disinfection after an examination. MRI technicians who have been in close contact with COVID-19 patients should receive strict medical observation for two weeks.

Conclusions: To prevent and control the potential hospital infection during the MRI examination for COVID-19 patients, a solution including five aspects was initially proposed.

Keywords: COVID-19; magnetic resonance imaging (MRI); prevention and control; protective devices

Submitted Mar 29, 2020. Accepted for publication Jul 21, 2020.

doi: 10.21037/atm-20-2945

View this article at: http://dx.doi.org/10.21037/atm-20-2945

\section{Introduction}

Since December 2019, a cluster of patients with pneumonia of unknown etiology has been reported in Wuhan city of the Hubei Province, China. Recently, the World Health Organization officially named it corona virus disease 2019 (COVID-19), which mainly cause damage to the lungs (1-3).
Chest computed tomography (CT) and digital radiography (DR) play important roles in the diagnosis and treatment of COVID-19. Accordingly, the examination procedures and preventive and protective measures in the situation of COVID-19 have been relatively mature for CT and DR. However, magnetic resonance imaging (MRI) examination 

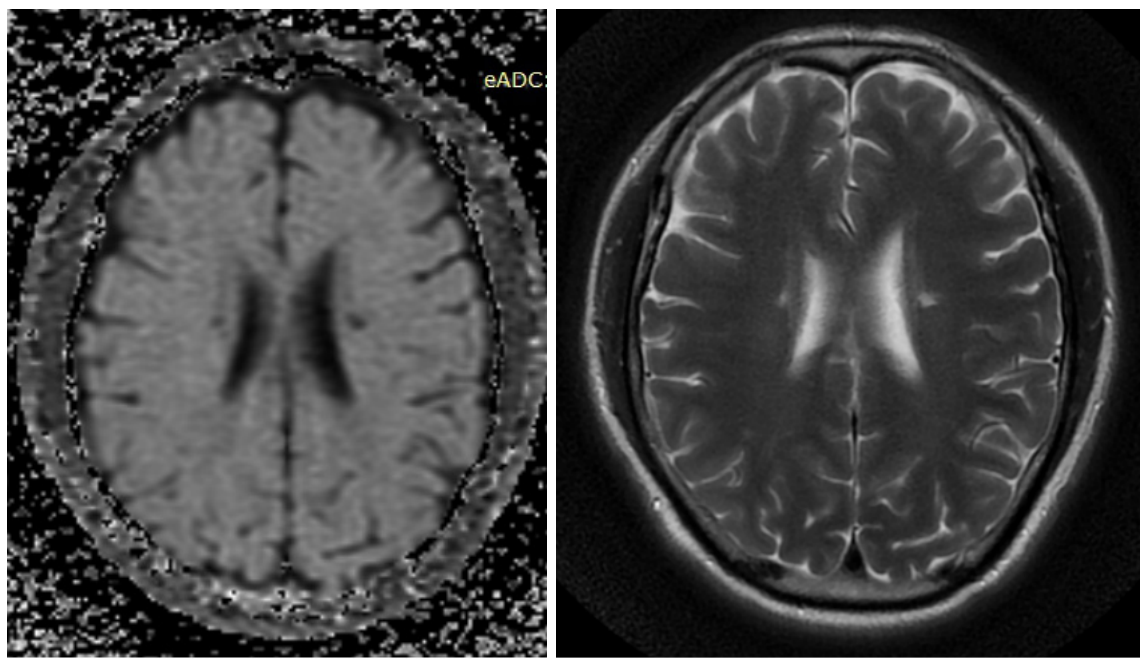

Figure 1 Brain MRI. Small necrotic and ischemic lesions were scattered on both sides of the basal ganglia and the centrum semiovale seen on T2-weighted image (T2WI) and apparent diffusion coefficient (ADC) map.

procedures and related preventive and protective measures of COVID-19 infection have not been reported yet.

Recently, two critically ill COVID-19 patients in our hospital, who were confirmed by positive nucleic acid tests of sputum samples, underwent MRI examinations due to their necessary clinical need. MRI examinations for COVID-19 patients, protection of medical personnel and disinfection of MRI equipment is a challenging process due high contingency of the disease. Keeping this in view, we initially formulated solutions about the procedure and necessary preventive and protective measures for MRI examination of COVID-19 patients for peer reference, with the help of experts from our hospital infection-control department.

We present the following article in accordance with the MDAR reporting checklist (available http://dx.doi. org/10.21037/atm-20-2945).

\section{Methods}

The study was conducted in accordance with the Declaration of Helsinki (as revised in 2013). The study was approved by the Clinical Research Ethics Committee of the First Affiliated Hospital, College of Medicine, Zhejiang University (No. IIT20200260A) and informed consent was waived.

\section{Patients data}

Case 1, male, 51 years old, a critically ill patient with
COVID-19, recently developed symptoms of mental abnormalities. After consultation with the department of mental health, a brain MRI scan was recommended. MRI showed lacunar infarct and ischemia. Cerebrospinal fluid analysis revealed 10 karyocyte cells/uL (reference value $0-8 / \mathrm{uL}$ ) and 700 red blood cells/uL, with IgG antibody-positive indicating the COVID-19 infection, clear and colorless appearance, negative Pandy's test and no bacterial growth after 5 days of culture (Figure 1).

Case 2, male, 59 years old, a critically ill patient with COVID-19, 2 years after liver transplantation, with cholestasis. After consultation with a hepatobiliary surgeon, MRCP examination was recommended. The result demonstrated multiple low signal intensity on T2-weighted images in the common bile duct, indicating previously inserted biliary stents. The bilirubin level decreased after stents were removed by ERCP (Figure 2).

The patient transport route from the ward to the MRI room was strictly implemented in accordance to the requirements of the hospital infection-control department. The accompanying doctor was wearing personal protective equipment.

\section{Suggestion and discussion}

Combining the above two cases and other literature, we proposed the following specific examination procedures and preventive and protective measures for MRI scanning of COVID-19 patients. 


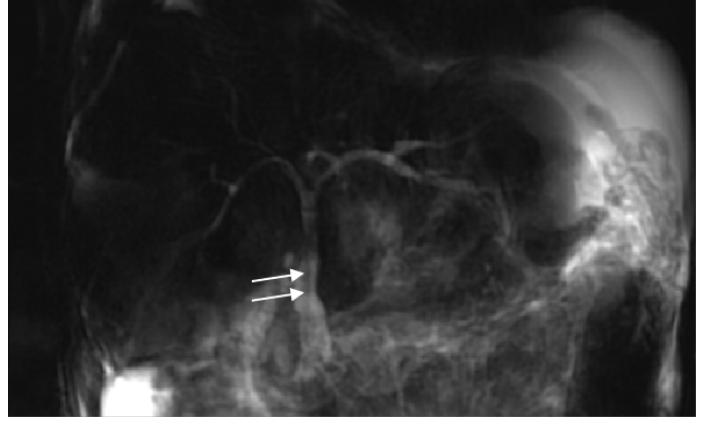

Figure 2 Two dimension (2D) magnetic resonance cholangiopancreatography (MRCP). There are multiple low signal intensity (arrows) in the extra-hepatic bile duct on heavy T2-weighted image, with clear and slight dilatation of intra hepatobiliary tree. The pancreatic duct was seen with slight dilatation.

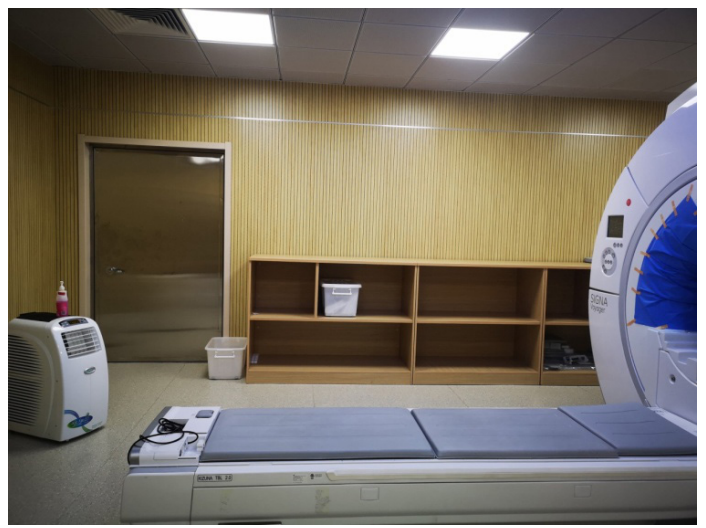

Figure 3 The MRI coil closets emptied before scan to prevent contamination of other coils. Plasma air sterilizer is placed at a safe place outside the 5 Gauss line.

\section{Layout requirements for the MRI room in the radiology department}

According to the specific layout of the MRI room in the radiology department of each hospital, specific areas should be set up including contaminated area, e.g., MRI scanning room, waiting area, transport passage, elevator and toilet for patient; potentially contaminated area that may be contaminated by pathogenic microorganisms, such as the area where the isolation gowns were put off; buffer area that is between the potentially contaminated area and the locker room; and the clean area, e.g., locker room, office, diagnostic room, on-call room, toilet and bathroom, etc. The personnel infection prevention and environmental disinfection procedures should be well arranged according to the different areas. Once the MRI scan is finished, the isolation gown is removed firstly in the contaminated area. The protective clothing, boot covers and outer gloves are removed and clean gloves are put on in the potentially contaminated area. Then, the mask, hat, goggles and inner gloves are removed in the buffer zone. Hand hygiene must be carefully performed before each step. Once the procedures are completed in the potentially contaminated and buffer areas, air disinfection machine and ultraviolet disinfection lamp should be turn on in these two areas. Finally, personal clothing should be put on after bathing in the locker room.

A dedicated transportation route for patients must be arranged and separated from staff channel. Unnecessary passages are needed to be closed. After wearing personal protective equipment, medical staff are restricted to move only with in the contaminated and potentially contaminated areas. Alcohol-based hand sanitizers should be placed inside and outside the doors in all areas, and all staff's hands must be disinfected when entering or leaving any room (4-10).

\section{Preparation before admission}

(I) Any coils and other tools that were temporarily unnecessary in the MRI room should be taken out of the room in advance to reduce the chance of contamination (Figure 3).

(II) As it is difficult to manually wipe the long MRI magnet, risk of cross infection may increase after COVID-19 patient scan. Therefore, it is recommended to use a double-sided tape to stick the two-layer disposable hospital bed sheets on to the entire inside wall of the magnet hole, preventing the potential contamination caused by the droplets if the patient coughs during scanning (Figure 4).

(III) The air conditioner in the MRI scanning room and the ventilation equipment in the machine should be turned off while scanning, as suggested by the department of infection-control in the hospital. The air conditioner should be turned on again after 48 hours from completion of the MRI scan and disinfection.

(IV) If possible, it is better to have a fixed MRI scanning room to receive suspected or confirmed COVID-19 cases, reducing risk of cross infection. An MRI room with an independent control room (operating room) has the priority to be selected 


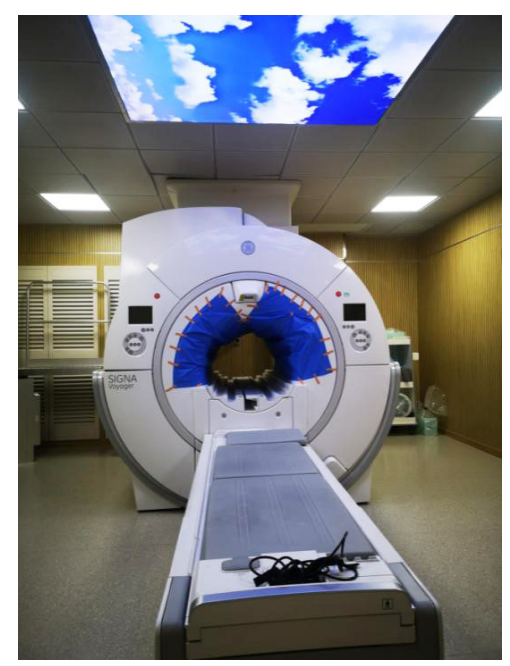

Figure 4 The entire inside wall of the magnet hole was stuck by the two-layer disposable hospital bed sheets to prevent the potential contamination caused by the patient's cough droplets during scanning.

for COVID-19 patient scan. If it is not the case, other scan rooms connecting to the control room should also be disinfected simultaneously when disinfecting after MRI scan.

(V) Two MRI technicians should be arranged, one in the control room to perform the scan, other in the scanning room to place the patient. The technician in the scanning room should properly put on his personal protective equipment.

\section{Preparation of medical staff}

After the MRI staff on duty receives a call from a clinician inquiring an MRI examination (the no-touch work mode is used between various departments in the hospital), the staff should make sure whether the patient is a suspected or confirmed COVID-19 case. Then, the exact time for MRI scan is scheduled and preparation work is started for the examination. First of all, MRI technicians complete their own protection procedures in the clean area, including wearing N95 mask, disposable hat, goggles, medical protective clothing, isolation gown, boots and double gloves (7). The air disinfection machine and ultraviolet disinfection lamp are then turned on after entering the buffer and potentially contaminated areas, respectively.

An MRI technician enters the scan room through the outside shielded door and the medical mobile air disinfection machine should be turned on, placed in a safe area outside the 5 Gauss line. A disposable hospital bed sheet should be put on the MRI bed for the isolation between the equipment and the patient, reducing contact transmission of virus. The medical waste container should be covered with double yellow medical waste disposal plastic bags. After adequate preparation, the technician waits for the patient at the door outside the scan room and guides the patient into the room as soon as the patient arrives at the designated waiting area. The inside shielded door of the scan room should always be kept closed. The technician in the scan room communicates with the one in the control room via intercom to confirm the patient's identity and the body location to be scanned. The technician after placing the patient in the MRI machine, waits outside the room until the scan is finished. Alcohol-based hands sanitizer should be used immediately after each contact with the patient. The handles of shielded door should be also disinfected.

\section{Preparation of patients}

(I) In addition to exclude the contraindications for MRI scan, the COVID-19 patient needs to put on personal protective equipment including medical protective clothing, hat, surgical mask, gloves, and shoe covers with the help of medical personnel. It is important to pull the wire of patient's surgical mask off and to cut the zipper of medical protective clothing off. Furthermore, the gap between non-wire mask and face must be taped for the prevention of air leakage.

(II) For a patient with claustrophobia, it is necessary to offer psychological persuasion in advance, and ask for the doctor in charge to accompany the patient during the examination, providing greatest security for our patient.

(III) It may be really tough for severely and critically ill COVID-19 patients to hold the breath when performing some scans, for instance, the MRCP. In such case, the technician needs to solve the problem by choosing the adequate scan sequence.

\section{Terminal disinfection after MRI scan}

(I) All disposable items in the magnet room are equal to infectious medical waste, and must be strictly handled in accordance with Chinese Regulations on the Administration of Medical Wastes and Measures for Medical Wastes Management of 
Medical and Health Institutions.

(II) Current understanding of the physical and chemical properties of the coronavirus are mostly based on the study on SARS-CoV and MERS-CoV. The virus is sensitive to heat and is effectively inactivated by $56^{\circ} \mathrm{C}$ for 30 minutes, by lipid solvents such as $75 \%$ ethanol, chlorine-containing disinfectants, peracetic acid and chloroform (11). However, the virus cannot be inactivated by chlorhexidine. The MRI machine surface, bed, coils, cushions and other related items should be cleaned twice with disinfecting wipes containing $75 \%$ ethanol. If there is dirt or visible stains, a disposable absorbent material should firstly be used to remove them completely, followed by disinfection as mentioned above. The area under the MRI scan bed should be disinfected specifically, because the bed has to move during the scan and therefore cannot be covered by the disposable sheet.

(III) The floor of MRI room should be mopped with disinfectant solution containing 2,000-5,000 mg/L effective chlorine. Other stuff in the MRI room should be wiped with the same concentration of disinfectant. The scanning room door should be closed and the air in the room should be disinfected continuously with a medical mobile air disinfection machine for more than 3 hours, two or more times a day.

(IV) Considering the potential risk of incomplete disinfection due to the long MRI magnet, the hospital infection-control department recommends that the scanning room should be closed for 48 hours after disinfection before next MRI scan is performed.

(V) The waiting area and passage way including railings, door handles, windows, and switches, etc., should be disinfected with disinfectant solution containing 2,000-5,000 mg/L effective chlorine.

After the scan is completed, the two MRI technicians have to stay in the specific isolation ward for medical observation of two weeks and are forbidden to leave the designated area during this period. After two weeks quarantine, they can leave the designated isolation area and end medical observation if they show normal conditions and two negative results for nucleic acid detection of the corona virus at day 1 and day 14 respectively.

\section{Results}

It is a challenge for COVID-19 patients to undergo MRI examination, which demands more complicated measures for the prevention and control of hospital infection than those for CT and X-ray examinations. Five aspects regarding the infection prevention and protection are recommended for MRI scan, including layout requirements in the MRI room, preparation before admission, preparation of medical staff, preparation of patients, and terminal disinfection after an examination, in order to prevent spread of infection in the hospital. Radiology personnel should strictly abide by the regulations on infection prevention and control. MRI technicians who have been in close contact with COVID-19 patients should receive strict medical observation for two weeks.

\section{Conclusions}

To prevent and control the potential hospital infection during the MRI examination for COVID-19 patients, a solution including five aspects was initially proposed.

\section{Acknowledgments}

Funding: This work was supported by the National Key R\&D Program of China (grant number 2017YFC0108700).

\section{Footnote}

Reporting Checklist: The authors have completed the MDAR reporting checklist. Available at http://dx.doi.org/10.21037/ atm-20-2945

Data Sharing Statement: Available at http://dx.doi. org/10.21037/atm-20-2945

Conflicts of Interest: All authors have completed the ICMJE uniform disclosure form (available at http://dx.doi. org/10.21037/atm-20-2945). The authors have no conflicts of interest to declare.

Ethical Statement: The authors are accountable for all aspects of the work in ensuring that questions related to the accuracy or integrity of any part of the work are appropriately investigated and resolved. The study was conducted in accordance with the Declaration of Helsinki (as revised in 2013). The study was approved by the Clinical Research Ethics Committee of the First Affiliated Hospital, College of Medicine, Zhejiang University (No. IIT20200260A) and informed consent was waived. 
Open Access Statement: This is an Open Access article distributed in accordance with the Creative Commons Attribution-NonCommercial-NoDerivs 4.0 International License (CC BY-NC-ND 4.0), which permits the noncommercial replication and distribution of the article with the strict proviso that no changes or edits are made and the original work is properly cited (including links to both the formal publication through the relevant DOI and the license). See: https://creativecommons.org/licenses/by-nc-nd/4.0/.

\section{References}

1. Li Q, Guan X, Wu P, et al. Early Transmission Dynamics in Wuhan, China, of Novel Coronavirus-Infected Pneumonia. N Engl J Med 2020;382:1199-207.

2. Rothe C, Schunk M, Sothmann P, et al. Transmission of 2019-nCoV Infection from an Asymptomatic Contact in Germany. N Engl J Med 2020;382:970-1.

3. Chan JF, Yuan S, Kok KH, et al. A familial cluster of pneumonia associated with the 2019 novel coronavirus indicating person-to-person transmission: a study of a family cluster. Lancet 2020;395:514-23.

4. Yu JM, Zeng YM, et al. Medical imaging examination technology. People's Medical Publishing House, 2016.

5. Technique standard for isolation in hospitals. National Health Commission of the People's Republic of China. Available online: http://www.nhc.gov.cn/wjw/ s9496/200904/40116.shtml. Published April 1, 2009. Updated April 23, 2009. Accessed March 1, 2020.

6. Specification of hand hygiene for healthcare workers. National Health Commission of the People's Republic of China. Available online: http://www.nhc.gov.cn/wjw/ s9496/202002/dbd143c44abd4de8b59a235feef7d75e. shtml. Published November 26, 2019. Updated February 19, 2009. Accessed March 1, 2020.

Cite this article as: Shen $\mathrm{X}$, Meng J, Wang Q, Ni L, Zhong Z, Hu S, Chen F. Coronavirus disease 2019: MRI examination procedures and infection prevention and protection. Ann Transl Med 2020;8(17):1074. doi: 10.21037/ atm-20-2945
7. Technical Guide for Medical Establishments in the Prevention and Control of the Transmission of the Novel Coronavirus (1st Edition). National Health Commission of the People's Republic of China. Available online: http:// www.nhc.gov.cn/xcs/zhengcwj/202001/b91fdab7c304431 eb082d67847d27e14.shtml. Published January 23, 2020. Updated January 23, 2020. Accessed March 1, 2020.

8. Clinical management of severe acute respiratory infection when novel coronavirus $(\mathrm{nCoV})$ infection is suspected, interim guidance. Available online: https://www.who. int/publications-detail/clinical-management-of-severeacute-respiratory-infection-when-novel-coronavirus(ncov)-infection-is-suspected. Published January 13, 2020. Updated January 13, 2020. Accessed March 1, 2020.

9. Infection prevention and control during health care when novel coronavirus $(\mathrm{nCoV})$ infection is suspected, interim guidance. World Health Organization. Available online: https://www.who.int/publications-detail/infectionprevention-and-control-during-health-care-when-novelcoronavirus-(ncov)-infection-is-suspected-20200125. Published January 25, 2020. Updated January 25, 2020. Accessed March 1, 2020.

10. Law of the People's Republic of China on the Prevention and Treatment of Infectious Diseases. The Central People's Government of the People's Republic of China. Available online: http://www.gov.cn/banshi/2005-06/27/ content_68756.htm. Published December 1, 2004. Updated June 27 2005. Accessed March 1, 2020.

11. Novel Coronavirus Pneumonia Diagnosis and Treatment Plan (Provisional 6thEdition). National Health Commission of the People's Republic of China. Available online: http://www.nhc.gov.cn/xcs/zhengcwj/202002/8 334a8326dd94d329df351d7da8aefc2.shtml. Published February 19, 2020. Updated February 19, 2020. Accessed March 1, 2020. 